IN brief

\section{Korea's 9 billion injection}

The Korean government has pledged nearly $\$ 9$ billion over the next 5 years to help domestic drug makers develop 20 new medicines, a set of strategies entitled Pharma Korea 2020. The government will give tax breaks to local pharma companies investing in $\mathrm{R} \& \mathrm{D}$, and $\$ 448$ million to help them expand their market presence and acquire overseas drug makers. Past annual investment in Korean pharmaceutical R\&D has been $\$ 860$ million from both government and private capital. To meet the Korea 2020 goals, Kyeong-ho Lee, chairman and CEO of the Korea Pharmaceutical Manufacturers Association, in a recent editorial, stressed the importance of attracting overseas talent and in-licensing drug candidates from international companies. He encouraged the industry to secure 20-30 new drug candidates from abroad in hopes of developing one global blockbuster, and focus on overseas mergers and acquisitions to expand local manufacturing and marketing capacity. Lee listed Israeli company Teva of Petach Tikva as an example worth emulating for its emphasis on generics, which analysts say is the foundation for Korea's growth plans. "Korean companies suffer from a lack of R\&D resources, and... the acquisition of biosimilar expertise is viewed as one way for companies to move up the added-value scale: from biosimilars, to bio-betters, to genuinely innovative drugs," said Robert McTiernan, a healthcare analyst with IHS of Englewood, Colorado. In June, local biotech Celltrion, of Incheon City, received positive recommendations from the European Medicines Agency for Inflectra and Remsima, biosimilars of blockbuster biologic Remicade (infliximab), made by Johnson \& Johnson of New Brunswick, New Jersey, for the same indications. In the same month, AstraZeneca of Cambridge, UK, expressed an interest in acquiring the Korean biotech.

\section{IN their words}

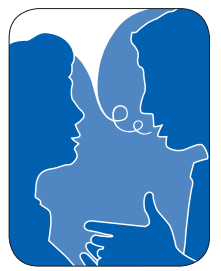

"We have a tremendous enthusiasm about the potential of stem cell therapy. That said, these aren't magical agents that run around your body and fix things." George Daley of Harvard voices his concerns over businesses touting stem cells as cures without scientific evidence to support their claims. (The New York Times, 9 September 2013)

"I'm very proud of what we are doing. I get upset when people start talking trash about what is done south of the border." Javier Lopez, founder of Tijuana's Regenerative Medicine Institute speaks of bias against his stem cell therapies. (The New York Times, 9 September 2013) current to block conduction at the affected nerve, and Fang reports that patients can receive anywhere from three hours to a day's worth of pain relief after remotely switching on the device in response to pain onset. The company is now awaiting FDA approval to embark on a pivotal trial for Altius next year.

Depression and other neuropsychiatric disorders could be tackled by implanted or external neuromodulators. The Cyberonics VNS implant has been approved by the FDA for use in treatment-resistant depression, although adoption is still relatively low due to lack of reimbursement support. NeuroSigma's wearable device could offer a more appealing solution for patients and insurers, and the company has reported that their eTNS system can deliver relief to patients with treatmentresistant depression, based on an open-label study in which 4 out of 11 patients went into remission (Epilepsy Behav. 28, 221-226, 2013).

Stimulating the trigeminal nerve also avoids most of the side effects that can arise from excess stimulation of the vagus, which regulates many other autonomic processes throughout the body. Furthermore, this facial nerve generally appears to be an important integrator in how humans respond to their environment. "In our positron-emission tomography studies, we have found that the areas of activation [from the trigeminal nerve] are very widespread," says Ian Cook, a UCLA researcher and NeuroSigma's senior medical advisor, "including areas profoundly important for things like regulating energy, sleep-wake cycles and appetite, as well as emotion, attention and concentration." UCLA and NeuroSigma are cooperating in pilot studies using their device eTNS for treating post-traumatic stress disorder and attention-deficit hyperactivity disorder.

At the University of Wisconsin's Tactile Communication and Neurorehabilitation Laboratory (TCNL) in Madison, scientists are applying peripheral nerve stimulation to tap into the brain's plasticity to treat symptoms from various neurological disorders. Yuri Danilov, Mitchell Tyler and Kurt Kaczmarek have devised a system that acts on the CNS by stimulating the tongue's dense network of nerve endings using an array of electrodes. "The tongue is connected directly to the brain via the brain stem through two cranial nerves," explains Danilov, "and the brain stem is essentially a master control center." This technology was initially tested in balance-impaired patients to 'coach' the brain in temporarily recovering directional sense, but the effects proved surprisingly enduring. The team is now embarked on more extensive studies pairing neurostimulation with physical and cognitive training for trau- matic brain injury in Iraq and Afghanistan veterans and with Baylor College of Medicine for Parkinson's disease.

Inflammation is also amenable to neurostimulation treatment. One company, SetPoint, bases its strategy on research from Kevin Tracey, of The Feinstein Institute for Medical Research in Manhasset, New York, who first identified an anti-inflammatory response to VNS in 2000 (Nature 405, $458-462,2000$ ) by uncovering an extensive axis of neuro-immune regulation. Now, the Valencia, California-based company is exploring VNS as an alternative to costly biologic drugs for autoimmune inflammatory conditions such as rheumatoid arthritis. "You can start to affect the function of the immune cells with very brief periods of stimulation," explains chief medical officer Ralph Zitnik. "We've reported that even a minute once a day to four times a day can give us clinical responses in RA [rheumatoid arthritis]." This also mitigates the potential side-effects of prolonged VNS, and patients to date have reported only transient discomfort at worst during stimulation. In an openlabel pilot study in Europe, six out of eight rheumatoid arthritis patients showed significant clinical improvement and two of the six essentially experienced remission.

Despite the promise that many patients might one day be able to modulate their health from a smartphone-sized device, progress has been limited by the realities of the startup world and the fundamental challenges of bringing new medical devices to market. Many companies have improvised solutions to affordably test the principles underlying their technology before investing in a prototype. For example, SetPoint has been doing its early studies with the FDA-approved Cyberonics VNS implant, whereas Neuros Medical employed a bulky external pulse generator connected to peripheral nerves through implanted electrodes with a minimally-invasive percutaneous interface, developed at nearby Case Western Reserve University. "We wanted to test the feasibility of whether we can relieve pain," says Fang, "so we spent a year getting that system done and not even a million dollars in development, and that way we were able to get into our first human subjects." Both companies have since designed proprietary devices for use in future pivotal trials.

Also, FDA regulations set an extremely high and costly bar for device approval, and many companies are finding Europe a better route to market initially. "It is still less expensive to do things in Europe," says Lima, "which is amazing - we never expected that."

Michael Eisenstein Philadelphia 